\title{
QUEM TEM DIREITO AO TERRITÓRIO?
}

\author{
WHO HAS THE RIGHT TO THE TERRITORY? \\ ¿QUIÉN TIENE DERECHO AL TERRITORIO? \\ Gloria Maria Vargas - Universidade de Brasília - Brasília - Distrito Federal - Brasil
yoya@uol.com.br
}

\section{Resumo}

A partir de uma visão normativa do território, apresentam-se três abordagens sobre os direitos territoriais que especificam o sujeito desses direitos. A primeira delas, a estatista ou funcionalista, tributária das visões hobbesiana e lockeana do estado, privilegia o estado como detentor dos direitos ao arguir que eles são produto de uma delegação da comunidade política, realizada no momento em que se pactua o contrato social. A segunda, culturalista, baseia-se nas relações simbióticas desenvolvidas entre os grupos culturais e 0 território num processo de agregação de valor material e simbólico em que se constroem identidades e pretensos direitos sobre o território. A última abordagem, a nacionalista, reconhece a importância da cultura como parte do processo de construção do sujeito de direitos, porém destacando a importância da definição de uma identidade política, como nos grupos nacionais, para a definição dos direitos territoriais.

Palavras-chave: Território, direitos territoriais, estado.

\begin{abstract}
From a normative perspective of territory, we present three approaches to territorial rights that specify the subject entitled to them. The first is the statist or functional view, stemmed from Hobbesian and Lockean visions of state, that privileges the state as holder of these rights considering it is delegated to it by the political community when forming consensus on the social contract. The second, or the culturalist approach, is based on the simbiotic relations developed between cultural groups and territory in a process of material and symbolic value gaining where identities are formed and territorial rights intended. The last one is the nationalist view that recognizes the importance of culture as part of the construction process of the subject of rights, highlighting the significance of a political identity definition, as in nations, in order to define territorial rights.
\end{abstract}

Keywords: Territory, territorial rights, state.

\section{Resumen}

A partir de una visión normativa del territorio, se presentan tres enfoques sobre los derechos territoriales que especifican el sujeto de esos derechos. El primero, llamado de estatista o funcionalista, es tributario de las visiones hobbesiana y lockeana del estado, y privilegia este último como detentor de los derechos al argumentar que ellos son producto de una delegación de la comunidad política realizada en el momento de pactar el contrato social. El segundo, culturalista, se basa en las relaciones simbióticas desarrolladas entre los grupos culturales y el territorio en un proceso de agregación de valor material y simbólico en el que se construyen identidades y posibles derechos sobre el territorio. El último enfoque, el nacionalista, reconoce la importancia de la cultura como parte del processo de construcción del sujeto de derechos, pero destaca la importancia de la definición de una identidad política, como en el caso de los grupos nacionales, para la definición de los derechos territoriales.

Palabras clave: Territorio, derechos territoriales, estado. 
Introdução

O território aparece e desaparece da literatura geográfica de tempos em tempos. Em diferentes momentos do desenvolvimento do pensamento geográfico, ele é entendido e usado com acentuações diversas, em grande medida a partir da compreensão em voga do termo espaço. É compreensível que assim seja se consideramos que os conceitos são suscetíveis a interpretações que dependem de teorias e meta-teorias que entram e saem de cena também.

Da perspectiva das outras ciências sociais, não é incomum encontrar uma naturalização do conceito de território, quando não uma completa omissão da sua conceituação. De uma maneira geral o território é tratado como um recurso material, sinônimo de solo ou terra, ou como um atributo fixo.

Com isto em mente, o objetivo deste artigo é tratar o território de maneira relacional, visando um diálogo com aspectos da teoria política e até da filosofia política. A quase total ausência de conexão com as áreas mencionadas chega a ser enigmática. Não pretendo aqui explicá-la, apenas constato o fato e externo minha perplexidade. Essa distância deixa um vazio grande na Geografia, principalmente na geografia política, de diversas formas. A primeira delas e quiçá a mais importante, é a ausência de uma abordagem do território que permita a sua compreensão e tratamento fenomênico, inserido no processo de formação dos Estados territoriais.

Há poucos autores que tratam dessa temática na Geografia, estando entre eles John Agnew, Stuart Elden, Saskia Sassen, Peter Taylor e Colin Flint (nem todos geógrafos, ainda que tratem de temas evidentemente geográficos). Isto leva a um segundo vazio: a ausência de um tratamento relacional do estado e do território no contexto dos fenômenos políticos contemporâneos. Recorrendo a uma analogia, a espacialidade dos fenômenos econômicos tem sido tratada relacionando o espaço e/ou o território ao capitalismo, em geral da perspectiva marxista, ainda que também seja possível relacioná-lo às perspectivas clássica ou neoclássica. No entanto, o território é tratado como categoria independente dos fenômenos políticos, com um pouco de voluntarismo, sem respaldo de teorias que lhe deem densidade.

Dizendo isto, começo a clarificar o que este artigo conterá. Devo antes esclarecer que ele faz parte de uma pesquisa cujo núcleo central é exatamente a procura de embasamento teórico para pensar o 
território como parte essencial do estado. Minha experiência docente na pós-graduação e a observação e constatação da necessidade e do desejo dos alunos de adentrarem a temática do estado como entidade política e espacial levaram-me à procura desse embasamento. Identifico a dificuldade de se tratar de aspectos políticos e geopolíticos sem a necessária compreensão das diferentes correntes da teoria política que explicam as variadas feições que o desenvolvimento do sistema estatal adquiriu desde o século XVI.

Visando completar esse vazio, dediquei-me nessa pesquisa a estudar três teorias políticas fundamentais para a compreensão do estado moderno: a teoria contratualista, a teoria utilitarista - ambas da corrente liberal -, e a teoria marxista, todas elas consideradas filhas do Iluminismo. Num primeiro momento, adotei a ideia de que essa taxonomia seria adaptável ao meu objetivo de pensar o território à luz dessas abordagens. Investigações posteriores me permitiram identificar uma dinâmica mais complexa que eliminou a simplicidade de tal propósito.

Acontece que a organização mencionada não permite fazer uma abordagem equivalente do território, em grande medida porque em nenhuma dessas teorias o território sequer é considerado. Os autores do contrato social - Thomas Hobbes, John Locke, John Rawls, Robert Nozick - dificilmente fazem considerações explícitas sobre o território, de forma que é apenas por inferências indiretas que se pode trabalhar o tema. Em geral, os autores das diferentes correntes concentram sua artilharia na análise do que seria uma comunidade política, e os baluartes que devem constituir o estado. O território é o elemento tácito (por vezes inexistente) em quase toda a literatura sobre Teorias do Estado.

Foi necessário, antes de tudo, compreender o que explica a ausência estrondosa do território nessa literatura. Minha hipótese inicial, e, portanto, suscetível de ser comprovada ou negada (na sua condição de hipótese) e de ser posteriormente substituída por outra mais fundamentada, é que há uma compreensão (equivocada) de que o que explica o estado é suficiente para tratar do território, como se o território não fosse um elemento substantivo e até causal na consolidação do estado. Na realidade, o território é subentendido como um dado conceitual que não precisa de abordagem explícita nas teorias do estado.

Nas suas formas e aplicações, a teoria política, em geral, pode ser normativa - isto é, se preocupa com as formas apropriadas da organização 
política e, na busca desse “dever ser” recorre à filosofia política - ou descritiva-explanatória, que tem uma forte ênfase na expressão fenomênica, isto é, nos fenômenos como eles são. Na prática, essas visões se misturam. Adotando a ideia de que a segunda vertente teria mais conexão com o território, mais uma vez só me deparei com omissões ao tema.

Como traçar, então, a relação entre estado e território? A seguir descrevo o meu percurso.

Do território ao estado, e de volta ao território

Não é um acidente que todos os estados, desde finais do século XVI, sejam territoriais. A ideia do estado, entendido como um aparato de governo, aparece no mundo antigo, especialmente em Roma, mas desaparece do pensamento político medieval. A noção de uma ordem impessoal e soberana, uma estrutura de poder legalmente circunscrita com jurisdição suprema sobre um território, não era possível enquanto o território fosse propriedade de monarcas ou dinastias e enquanto os direitos de propriedade e políticos estivessem atrelados à tradição religiosa. De igual maneira, foi necessário que os súditos das monarquias e impérios se convertessem em indivíduos e em "povo", para que a noção de estado se concretizasse num ente político e material de fato (Held, 1989).

Os Estados precisam do território por várias razões. A primeira delas é que assim se configuram, isto é, adquirem uma forma. Além da forma, concretizam um conteúdo, que é a comunidade política. Sem o território, o Estado se descaracterizaria, perderia o elemento que o sustenta como entidade física, como materialidade. Para além da sua materialidade, não poderia identificar os seus constituintes, a sua comunidade política, pois esta se assenta, se localiza, no território.

Note-se que neste raciocínio se explicita um imperativo entre o estado e o território de forma que este último é razão necessária, porém não suficiente para o primeiro. Talvez seja por esta relação de necessidade, porém não de suficiência, que o território tenha sido o membro recorrentemente ausente nas teorias do estado. Aceito este imperativo, surgem questões sobre como se estabelecem as relações de necessidade do estado e do território e como essas relações se legitimam da perspectiva dos princípios e dos direitos que se adquirem quando se constituem comunidades políticas. 
Para pensar estas questões é crucial definir o âmbito ou limites destas reflexões. A etimologia de uma palavra é um bom lugar para se começar uma reflexão. Território vem do latim territorium, derivado da combinação das palavras terra, e torium, que significa "pertencer a” (Taylor, 1985). Terra a qual se pertence, pode bem ser o significado genérico. De outra parte, a palavra estado, deriva do latim status, e na sua acepção medieval foi usada para denotar o estado ou condição pessoal dos governantes ou, numa segunda conotação, a condição do âmbito ou domínio de um unidade política independente (Skinner, 1989). A palavra foi adquirindo outros significados e feições e, modernamente, o estado se entende como uma forma de organização política coletiva, que se distingue dos governantes e dos governados e que exerce o poder sobre uma área geográfica específica.

Notem que nessas definições se entrelaçam três elementos: uma área geográfica delimitada, uma comunidade e uma autoridade política que a governa. A relação entre o estado, o território e a comunidade política não deve ser tratada como um a priori, pois assim, constitui-se numa premissa, numa asseveração não sujeita a questionamentos. Pense-se na possibilidade de se ter estruturas de autoridade política não ligadas a uma área geográfica. O que seria um mundo não dividido em estruturas territoriais, nas quais há uma autoridade política que representa uma coletividade? Como seria um mundo sem divisões territoriais, com uma única autoridade política? Ou múltiplas comunidades políticas não ligadas a áreas geográficas determinadas? Em outro espectro de ideias, pense-se no que acontece quando há movimentos secessionistas cuja estratégia consiste em interromper a continuidade territorial de um Estado para dividi-lo e criar, na área secionada, outra autoridade política que represente a coletividade ali assentada. Todos esses casos hipotéticos são plausíveis. E em todos eles há um fator de conexão: o vínculo estreito entre estado e território. Para tratar desse vínculo, as teorias normativas são mais explícitas quanto ao termo ausente, o território, do que as descritivas explanatórias, embora, como normativas, o foco não seja o território propriamente, mas os direitos territoriais.

No contexto normativo entre o estado, o território e a comunidade política, a pergunta- chave é por que o estado, e não outra forma política ou pré-política, tem direitos territoriais sobre a área geográfica onde se assenta uma comunidade política? Outras questões derivam-se dela: por que o 
estado adquire jurisdição suprema sobre o território, o que lhe confere a capacidade de administrá-lo e controlá-lo? Como a relação estadoterritório se fenomeniza nas diferentes formas estatais? Por que não é a própria comunidade política, ou um grupo étnico ou nacional, que reclama para si os direitos territoriais? Essas questões não têm respostas únicas. A existência de conflitos que se arrastam por décadas corrobora esta indeterminação e atesta a importância do assunto. As disputas territoriais, os processos de secessão, de colonização e descolonização, todos refletem uma carência conceitual, em grande parte vinda da omissão tanto da teoria política quanto da própria geografia. A procura por respostas nos levou ao estudo de uma literatura que aborda estas questões. Uma síntese dela é o que se apresenta a seguir.

\section{Abordagens teóricas}

As abordagens sobre direitos territoriais podem ser sintetizadas em três vertentes, que apresentamos a continuação. A estatista ou funcionalistas, a culturalista e a nacionalista. Cada uma delas será abordada de uma perspectiva puramente teórica, não considerando a causalidade histórica nem sua validez nos assuntos jurídicos, pois isto constituiria material tão abrangente, que, primeiro não conhecemos devidamente e, segundo, transcende aos objetivos deste artigo.

\section{A abordagem estatista}

Esta abordagem, também chamada de funcionalista e contratualista, tem suas raízes na perspectiva da teoria política de Thomas Hobbes, um dos primeiros autores do contrato social, e a sua visão de estado e sociedade. Ele também foi um dos primeiros a identificar o que seria o poder público; uma forma de estado, que ele chamou de um "homem artificial”, definido pela sua permanência e soberania que "dá vida e movimento à sociedade e ao corpo político" (Hobbes, 2014, p. 8).

Na sua obra Leviatã ou Matéria, poder e forma de um Estado Eclesiástico e Civil (2014 [1651]), Hobbes começa por traçar uma série de postulados sobre a natureza humana, que considerava profundamente autocentrada e egoísta. Este aspecto tem um peso enorme na sua visão, e é por estas características intrínsecas que ele considerava a possibilidade de 
cooperação entre as pessoas muito limitada. Em contraposição, considerava existir no ser humano uma busca incessante por poder na procura da autossatisfação. Pelo fato do poder ser de soma zero, isto é, o poder de um é a submissão do outro, os conflitos de interesse eram, na sua visão, não apenas inevitáveis, mas um fato da natureza. A procura pelo poder definia a condição humana (Held, 1989). A luta constante pela sobrevivência se dá neste contexto que faz com que o homem esteja condenado a uma vida de solidão, pobreza e brutalidade. Esta foi a caracterização do que ele chamou de estado de natureza. É o "estado de guerra; e uma guerra que é de todos os homens contra todos os homens. Pois a guerra não consiste apenas na batalha, ou no ato de lutar, mas naquele lapso de tempo durante o qual a vontade de travar batalha é suficientemente conhecida" (Hobbes, 2014, p. 15). A guerra não é necessariamente guerra declarada, mas uma constante disposição beligerante (Held, 1985).

Sendo assim, Hobbes reconhece a necessidade de que os indivíduos procurem formas claras e inteligíveis para se ter paz e segurança, elementos fundamentais para a construção e viabilização de uma vida em comum. No entanto, como procurar esses elementos quando os interesses são contraditórios e há uma busca pela autossatisfação que não considera o interesse comum? A resposta a esta pergunta o levou à criação do Leviatã: uma autoridade poderosa à qual os indivíduos rendem e transferem seus direitos num pacto, que, constituído, forma duas esferas independentes, a sociedade e o estado. $\mathrm{O}$ contrato social, ou pacto, consiste em passar os direitos de autogoverno a essa única autoridade, que será autorizada a atuar em nome do coletivo. Cria-se um poder político único, o do soberano que adquire o direito do exercício legítimo do poder sobre os indivíduos. O soberano é uma posição produto do contrato social e a soberania é, antes de tudo, uma qualidade dessa posição e não da pessoa que a ocupa (Held, 1989, p. 16).

O contrato social é contraído uma única vez e a autoridade criada determina a natureza e os limites do poder, limites determinados pelo território onde a comunidade política se assenta. Mas os limites são também os da eliminação da submissão do homem pelo homem e a formalização da submissão ao poder do estado, concretizado em leis, que fazem surgir a comunidade de direito. Através do soberano, uma pluralidade de vozes e interesses se converte numa única vontade, de tal forma que falar em estado soberano implica em falar em uma unidade política materializada num território. 
O Leviatã, como autoridade soberana, cria as leis da sociedade e separa o justo do injusto. Esses são os seus deveres. O que ele recebe em troca? O direito de governar sobre a área geográfica onde se assenta a comunidade política. Daí em diante, o estado detém os diretos sobre o território. Isso significa ter autoridade legítima para garantir a paz e a segurança, propósito primeiro da soberania, e ser o detentor do poder coercitivo sobre a comunidade política. Os direitos sobre o território marcam o exercício da soberania do estado e determinam o controle dos limites e fronteiras onde a autoridade soberana se encontra com as outras autoridades contíguas. Isto origina a comunidade de estados.

A ideia hobbesiana que instaura a relação entre comunidade política, estado e território, permeia a ordem internacional e molda o mapa do mundo em um sem-número de estado territoriais que alojam suas comunidades políticas. A história territorial moderna nos mostra que o poder, de fato, se territorializa em estados, pelo menos por enquanto, e que assim pretensamente, se mantém a paz e a estabilidade interna, em cada área geográfica.

Esta é a abordagem mais aceita na definição do sujeito dos direitos territoriais. As denominações dadas a ela evidenciam as origens e lógicas acolhidas para cada uma: é funcionalista porque supõe que as funções do estado, sempre que cumpridas, justificam os diretos territoriais sob sua potestade. É contratual porque a relação indivíduo-soberano se dá num contrato social tácito estabelecido e reafirmado entre as partes. E é estatista porque o sujeito dos direitos é o estado.

Outro autor importante e clássico do contrato social, necessário para compreender esta abordagem, é John Locke. Locke tinha uma ideia menos sombria da natureza humana. Para ele, o estado de natureza hobbesiano era indesejável, não tanto porque permitia a expressão do lado mais obscuro do ser humano, senão porque era ineficiente. O contrato social não era apenas a delegação de poder a um soberano para garantir a paz e a estabilidade, mas uma forma de construir consensos para que os frutos da terra fossem usufruídos por todos os homens em comum (Simmons, 1995).

Na sua visão, a fundação de uma sociedade política requeria o consentimento entre os indivíduos e o estado, sendo esta noção o centro de sua filosofia política. Nessa anuência tácita, os indivíduos delegam direitos ao estado, para a viabilização da comunidade política. Se a ênfase do contrato social para Hobbes estava no soberano a quem a coletividade subordinava-se para garantir a paz e a estabilidade, para Locke (1988) o 
importante é o vínculo consensual cujo objetivo é garantir os direitos individuais. Não há submissão a um Leviatã em troca de paz e estabilidade; há uma decisão racional e independente dos indivíduos que delegam poder ao estado para que este garanta os seus direitos individuais. Os direitos individuais a que se referia Locke são aqueles três que ele considerava inalienáveis, e que ele chamou de direitos naturais: o direito à vida, o direito à liberdade e o direito à propriedade. A delegação de direitos ao estado se faz para que eles sejam arbitrados e protegidos. No caso do direito à propriedade, interessa examinar o direito à terra. Locke entendia que o direito individual a sua posse não era afetado pelo contrato social, já que o que se delegava era a autoridade sobre ela, isto é, o direito do estado a estabelecer e fazer valer as leis que sobre ela regem, e não o direito individual a trabalhá-la e usufruí-la, sempre que no marco das leis. (Simmons, 1995).

Nota-se que ambas as visões supõem que, enquanto o estado cumpra as funções para as quais foi criado, são legítimos os seus direitos sobre o território. De um lado, porque assim propicia o bom funcionamento da sociedade em termos da sua segurança e estabilidade (Hobbes), e de outro, em termos da garantia dos direitos dos indivíduos (Locke).

A vertente estatista utiliza também elementos kantianos para legitimar a origem da autoridade do estado. Kant entendia que há necessidade do estado quando este cuida do bem comum e garante a justiça. Dessa perspectiva, o estado não está acima da sociedade, como na visão hobbesiana, mas do lado dela, quando é o garantidor da justiça. Para isto, a autoridade política deve ser capaz de estabelecer uma moldura de regras gerais que sejam livremente acatadas para, assim, constituir uma sociedade civil longe do estado de natureza. É no território que essa justiça é semeada e reiterada e, portanto, é ali que a autoridade política encontra a sua jurisdição. Os direitos territoriais do estado são legítimos, desde que a sociedade seja direcionada pela justiça e a procura do bem comum (Buchanan, 2004; Stilz, 2009).

Mais contemporaneamente, estes postulados do iluminismo são analisados por diferentes autores e correntes. Dentre eles, a Ana Stilz (2009), que avança a partir de Kant. Para ela, a provisão de justiça é condição necessária para que o estado tenha direitos sobre o território. Garantir a satisfação das necessidades e o cumprimento dos direitos humanos básicos são requisitos necessários para se ter justiça (Stilz, 
2009). Quando o estado cumpre as suas funções e é justo, isto é, quando garante o primado das leis e os direitos dos cidadãos, ele gera e cumpre obrigações políticas e deve, por conseguinte, manter os direitos sobre o território. Esses direitos territoriais são de jurisdição e de autoridade sobre os recursos.

Já Sidgwick (2005) expande a abordagem estatista sob uma perspectiva utilitarista. Para ele, o exercício de soberania do estado está relacionado aos direitos sobre o território e justificado por ser indispensável ao bom governo. Por sua vez, o bom governo significa criar bem-estar para a maior quantidade de pessoas. Há, portanto, um patamar de funções que o estado deve cumprir para que a autoridade sobre o território tenha legitimidade (Moore, 2015). Começa, obviamente, com o efetivo controle do território e se completa com a manutenção da ordem e garantia dos direitos individuais. Na medida em que essas funções sejam desempenhadas, o estado estará cumprindo o objetivo sine qua non da visão utilitarista, a de prover o maior bem-estar para a maior quantidade de pessoas.

A partir dessa lógica se fundamenta o princípio de integridade territorial que considera que cada estado é soberano e que o território que lhe dá materialidade é intocável. Com esse princípio, que é a base da lei internacional sobre a inviolabilidade do território, consolida-se a função mais reconhecida do estado territorial, que é a de prover segurança dentro das suas fronteiras. Há uma relativa facilidade em se reconhecer o estado como o agente coletivo, a partir das visões aqui discutidas, e que exprimem diferentes vertentes de pensamento político. $\mathrm{O}$ estado se apresenta com um ente que tem uma estrutura unificada e clara, com capacidade de implementar e fazer valer as decisões da coletividade. Assim sendo, resulta também fácil reconhecê-lo como o ente unitário que detém o monopólio da força, segundo a definição de Max Weber, e onde se delimitam, estabelecem ou se consentem os direitos individuais e coletivos. Na medida em que uma comunidade coopera, participa e decide sobre os destinos que lhe são próprios, organiza o convívio e constrói proto-instituições. Essas proto-instituições se aprimoram no tempo, desde que tenham uma materialidade que as sustente e as vincule com o grupo. Isto se realiza via a jurisdição do estado. Sem essa jurisdição, não há forma de organizar o convívio, não há como construir formas que permitam ao grupo sair do caos. Uma vez instituído o ato político do contrato social, constitui-se a ordem legal e de direito no território. Reconhecem-se os 
vínculos entre estado, território e comunidade política, comentados nesta abordagem. Essa seria a síntese dos argumentos.

No entanto, levado ao extremo, a visão funcionalista apresenta problemas. Suponha-se que um estado K garante e comprova que pode cumprir as funções melhor do que o estado Q sobre um mesmo território. Isso daria direito a $\mathrm{K}$ de assumir os direitos territoriais de $\mathrm{Q}$ ? O que daria o direito a Q de continuar sendo o sujeito dos direitos territoriais e de não deixar que K tome conta do seu território? Se o argumento funcionalista fosse suficiente, desde que K garanta a paz, a segurança, a justiça e os direitos da população, pode, em tese, assumir Q. Entretanto, não basta com que o estado cumpra as funções devidamente. Há de se considerar a relação mais profunda que se estabelece entre Q, a população e o seu território. Há também uma questão de autoridade política embutida. O estado Q desenvolveu uma autoridade política porque conquistou legitimidade ao longo dos anos. Legitimidade que não depende apenas dele cumprir suas funções melhor do que K (Moore, 2015). Na relação entre estado, território, comunidade política, a legitimidade não passa a existir apenas por razões funcionais. É necessário considerar o campo das representações e do simbólico. Estas considerações levaram a ampliar a compreensão das relações normativas com o território mediante as abordagens culturalista e nacionalista, que apresentamos em seguida.

\section{Abordagem culturalista}

Os argumentos funcionalistas ou estatistas também apresentam sérias restrições no sentido histórico. O fato de um estado cumprir as funções elencadas pode não ser uma constante histórica e, dessa forma, caso os valores que legitimam o estado mudem, como acontece de fato, perder-se-ia a legitimidade dos direitos territoriais. Isto cria um horizonte de instabilidade para a comunidade política que leva a enfatizar a necessidade de se considerar esta segunda abordagem. Ela estabelece que o sujeito dos direitos territoriais não deve ser o estado, mas uma comunidade que encarne um sujeito coletivo.

O desfio desta abordagem é estabelecer o agente com características trans-históricas que possa, de fato, ser sujeito coletivo de direitos. Teria de ser um grupo que se mantém coeso pelo mútuo reconhecimento, identidade comum e práticas compartilhadas. Essas características descrevem grupos culturais (Miller, 2012). 
Os grupos culturais desenvolvem os costumes, os hábitos e todas as suas características próprias por meio do contato, do uso e da transformação do território. Assim sendo, o território se constitui num elemento fundamental, não apenas para a sua sobrevivência, mas para a construção da sua identidade. Desenvolve-se uma relação simbiótica entre o território e a cultura, que serve de base para a construção de relações políticas e jurisdicionais. Ao longo do tempo, aprimoram-se as regras do coletivo com tudo o que diz respeito à sobrevivência e à convivência, sempre envolvendo a área geográfica e o próprio território onde a interação se desdobra, que dão sustento e recebem os acréscimos que a cultura grava neles. Entre esses acréscimos, estão a segurança e o controle da área geográfica (Miller, 2012). O controle sobre a área geográfica é fundamental para requerer os direitos territoriais, pois é a jurisdição sobre o território que gera os direitos sobre ele.

À vista disso, cria-se uma vinculação de três elementos, a cultura, o território e a jurisdição, que dá ao grupo cultural à possibilidade de reivindicar os direitos territoriais. A reivindicação inclui não só os direitos de posse da terra, mas também de autoridade sobre a área geográfica, autoridade que transforma a simples propriedade de um pedaço de terra em autoria sobre o território e, portanto, em reconhecimento do coletivo como sujeito de direitos (Miller, 2012).

Parece uma forma sensata para fazer valer direitos, já que reivindica o mútuo enriquecimento da cultura e da área geográfica com um coletivo sendo reconhecido como sujeito. Ao longo da interação do grupo com o território, aspectos objetivos do grupo cultural, tais como regras pelas quais se organiza e compromissos coletivos que adquire, e aspectos subjetivos, particularmente crenças, expectativas e anseios, interagem e se aprimoram. O desenraizamento ou o não reconhecimento desse processo simbiótico - via a imposição de direitos territoriais a uma autoridade alheia ao grupo - significaria a sua descaracterização cultural, e até a sua extinção.

Os críticos desta visão contra-argumentam. A primeira e mais evidente objeção é a dificuldade de se definir o que seria um grupo cultural. O processo de separar e individualizar culturas em conjuntos distintivos pode ser problemático. Não existe um conjunto de condições necessárias e/ou suficientes preestabelecido para fazer essas distinções, principalmente quando a distinção obriga a delimitar o conjunto de pessoas às quais pertenceriam os direitos sobre um território. 
Uma segunda objeção diz respeito à linha temporal em que a reivindicação cultural teria validade. Qual o tempo de assentamento necessário para considerar o grupo legítimo como sujeito de direitos de um território? Responder a esta pergunta envolve aspectos históricos difíceis de comprovar e de formalizar. Dificuldade que se transfere também à definição da jurisdição da área geográfica sob reivindicação.

Uma das críticas mais fortes a esta abordagem, no entanto, é que não se delimitam as características e elementos que os grupos culturais devem possuir para requerer direitos e, portanto, o número e tipologia de casos possíveis é muito amplo. Em tese, um grupo de imigrantes poderia reclamar jurisdição e direitos territoriais sobre a área geográfica que ocupa, se comprovar que a transformou com marcas culturais distintivas e desenvolveu relações de enraizamento nela.

Um exemplo pode mostrar este ponto com mais clareza. Na cidade de São Paulo, há vários grupos de imigrantes que têm se organizado em bairros, não apenas de habitação, mas de infraestrutura de indústria, comércio, serviços etc. Um dos mais famosos com uma população muito expressiva é o bairro da Liberdade, de imigrantes japoneses. No bairro da Liberdade, os japoneses têm desenvolvido uma paisagem onde se constata o nexo entre a área urbana e a cultura, de tal maneira que o bairro é nitidamente distinguível dos outros na cidade, tendo características próprias na sua morfologia e nas suas funções. É o resultado de uma verdadeira mistura entre a cultura e a terra urbana de assentamento dos imigrantes.

Segundo esta abordagem, os japoneses e filhos de japoneses do bairro Liberdade poderiam, teoricamente, reivindicar direitos territoriais. Isso significa que eles teriam a autoridade legítima para fazer a legislação que regeria o bairro, assim como para fazê-la cumprir. No entanto, esse não é o status quo do bairro, nem poderia ser sob as leis do Estado brasileiro. A autoridade sobre esse território está nas mãos do governo municipal, que por sua vez está inserido num Estado federativo que demanda deveres e direitos. Evidencia-se uma falta de aprimoramento nessa visão que permita diferenciar casos como o exposto de outros em que os argumentos culturais podem e devem, de fato, se contrapor às contestações de estados, em geral, muito consistentes. Isso permitiria a um povo que ocupa um território no qual tem agregado valor material e simbólico, com o passar do tempo, possa reclamar para si direitos territoriais e que estes lhe sejam reconhecidos. Todavia, a falta de uma definição que considere não apenas 
elementos culturais, mas também políticos, fragiliza esta abordagem. A necessidade de se ter uma identidade política, além da cultural, parece essencial para reivindicar direitos territoriais.

A razão desta necessidade está no fato de que a identidade política faz parte da fundação da comunidade política, pré-requisito para criar sujeitos de direito e de leis. Sem o fato político, não há direito nem legislação, pois o político os antecede. A identidade política serve de base para se organizar o âmbito político do grupo social que pode, a partir dessa identidade, se organizar politicamente de diferentes maneiras, dentre elas, como estado. É a identidade política que se expressa na defesa da jurisdição da área geográfica de assentamento e, portanto, na defesa do território. Defende-se aquilo sobre o qual se tem direito, daí que o aspecto político da identidade seja tão essencial. A próxima abordagem combina alguns desses elementos.

\section{Abordagem nacionalista}

O que dá direito ao estado de exercer autoridade sobre as fronteiras de um território? Para a abordagem nacionalista, o direito territorial do estado se deriva do direito coletivo da nação ao território, que se considera anterior. A nação pode ser definida como um grupo que compartilha crenças, tem compromissos mútuos, tem extensão histórica e características culturais e políticas partilhadas e reconhecidas pelos seus membros (Miller, 2012; Moore, 2015). Os direitos territoriais são um direito coletivo dos grupos nacionais baseados nos laços ou vínculos culturais e políticos com o território. Os vínculos de índole cultural são de identidade (Gans, 2007) e de residência (Meisels, 2003, Miller, 2012) e os políticos são criados a partir do desenvolvimento de projetos políticos conjuntos.

O vínculo identitário se desenvolve ao longo da história e está intimamente relacionado com as características do território. Essas características ou mesmo fatos ali ocorridos, fazem parte da construção da identidade coletiva, de tal maneira que o território pode chegar a ser visto como a pátria, em que a área geográfica adquire um valor acima do simples interesse de governo (Gans, 2007).

O vínculo de residência não surge apenas pela presença do grupo no território, mas pelas ações que realiza e que remodelam, reconfiguram e modificam a paisagem. Essas ações não apenas agregam valor à terra, 
mas são o suporte também das remodelagens culturais do grupo. A cultura do grupo vai sendo impressa no território, o que por sua vez reforça a sua identidade nacional. Os assentamentos ou residências construídas no território aumentam o significado cultural e político da nação, que se expressa além da remodelação da paisagem. O território impregnado de elementos da cultura nacional não apenas nas formas, refletirá também as funções e processos pertinentes ao grupo nacional. Já que os valores culturais nacionais desenvolvidos na paisagem não podem ser separados do território, o grupo nacional desenvolve um forte interesse em ter os direitos territoriais sobre a área geográfica onde se assenta.

Pode-se inferir, pelo dito, que esta abordagem permite reconhecer e demarcar fronteiras, segundo a extensão dos assentamentos. Isto posto, justifica-se a potestade dos direitos sobre o território específico. Neste sentido, a abordagem nacionalista se diferencia da abordagem estatista que apela aos argumentos de paz, estabilidade, segurança e justiça para reivindicar os direitos territoriais em cabeça do estado, porém sem justificar por que a reivindicação se faz sobre um território específico (pois, em tese, os bens públicos como paz, estabilidade segurança e justiça poderiam ser providos em qualquer território).

Nada obstante, esta abordagem não explicita o vínculo entre direitos individuais e coletivos ao reivindicar que o fato de agregar valor ao território geraria direitos coletivos, e não apenas individuais. O trabalho realizado sobre o território se faz de forma individual e, consequentemente, geraria direitos de propriedade sobre a terra, também individuais. Assim, mesmo que fosse considerada a transformação e a agregação de valor, não necessariamente haveria licença para reivindicar direitos de autoridade sobre o território.

Um exemplo ajuda a expor este questionamento: pense-se numa área baldia num estado preexistente, em que um grupo nacional se assenta e sobre a qual realiza as ações descritas: modifica a paisagem, agrega valor à terra, propicia um círculo virtuoso de enraizamento e fortalecimento da sua identidade cultural e política.,Se se lhe reconhecem direitos coletivos, esse reconhecimento geraria direitos territoriais, em se tratando de grupos nacionais. O estado que "aloja” esse grupo nacional perderia a jurisdição e a autoridade sobre a área baldia. Para os estados, pelo menos em teoria, haveria um grande risco em se ter terrenos baldios, pois seriam suscetíveis de serem colonizados e reclamados por grupos nacionais (Stilz, 2009). 
Estes argumentos dariam aos imigrantes alemães, portugueses, espanhóis etc., que chegaram ao Brasil no final do século XIX e começos do século XX, autoridade para reivindicar direitos territoriais. O fato de ter agregado valor à terra, reproduzido a sua cultura e ter tido um projeto político próprio seriam razões para tal.

\section{Considerações finais}

Então, no final das contas, quem tem direito ao território?

Os direitos territoriais, desde o Tratado de Vestfália, são reconhecidos primordialmente aos estados. Neste artigo, fizemos uma síntese das abordagens usadas para examinar a questão do ponto de vista da perspectiva normativa e, dessa maneira, pudemos inserir argumentações que privilegiam outros sujeitos como portadores dos tais. Os argumentos consideram a história das relações que os grupos estabelecem com o território e a terra, da perspectiva das suas características e do aprimoramento da identidade cultural e política que se retroalimenta a partir da simbiose gerada. Esses elementos não devem ser tomados isoladamente, mas considerados como parte de processos que se revertem em ações políticas fundacionais e abrem os caminhos da autodeterminação coletiva. E, segundo Moore (2015, p. 86), a autodeterminação precisa de um lócus que está em grande parte circunscrito ao lugar onde as relações entre as pessoas e das pessoas com o território efetivamente se dão.

Com esses elementos explícitos, consideram-se os argumentos essenciais das três abordagens: a necessidade de que o político gere uma forma de organização estatal que assuma funções de garantir a paz, estabilidade e justiça; a utilidade de que se constate um fato político que derive em alguma forma de sujeito político e de direitos não estatais e, por último, a premência de considerar o envolvimento cultural e identitário, que pode ou não ser nacional, para que a relação com o território seja digna de ser reivindicada.

\section{Referências}

BUCHANAN, A. Justice, Legitimacy and Self-Determination: Moral Foundations for International Law. Oxford: Oxford University Press, 2004. 
GANS, C. Is there a historical right to the land of Israel? Azure, v. 5762, n. 27, p. 1-5,, 2007. Disponível em: <http:www.azure.org.il/article.php?id=32>. Acesso em: 14 out. 2016.

HELD, D. Political Theory and Modern State. Standford, California: Standford University Press, 1989.

HOBBES, T. Leviatã ou Matéria, poder e forma de um Estado Eclesiástico e Civil. Tradução João Paulo Monteiro e Maria Beatriz Nizza da Silva. São Paulo: Marins Fontes, 2014. (Originalmente publicado em 1651).

MEISELS, T. Liberal Nationalism and Territorial Rights. Journal of Applied Philosophy, v. 20, n. 1, p. 31-43, 2003.

MILLER, D. Territorial Rights: Concept and Justification. Political Studies, v. 60, n. 2, p. 252-268, 2012.

MOORE, M. A Political Theory of Territory. New York: Oxford University Press, 2015.

NINE, C. A Lockean Theory of Territory. Political Studies, v. 56, n. 1, p. 148-165, 2008.

SIDGWICK, H. The elements of Politics. 3. ed, London: Elibron Classics, 2005.

SIMMONS, A. J. The Lockean Theory of Rights. Princeton: Princeton University Press. 1995.

SKINNER, Q. "The State”, in Political Innovation and Conceptual Change. BALL, T.; FARR, J.; HANSON, R. I. (Ed.). Cambridge: Cambridge University Press, 1989.

STILZ, A. Why do States have Territorial Rights? International Theory, v. 1, n. 2, p. 185-213, 2009.

TAYLOR, P. J. Political Geography: World Economy, Nation State and Locality. London: Longman, 1985. p. 94-140.

WALDRON, J. Theories of Rights. Oxford: Clarendon Press. 1984.

YPI, L. A Permissive Theory of Territorial Rights. European Journal of Philosophy, v. 22, n. 2, p. 288-312, 2012.

Gloria Maria Vargas - Possui Graduação em Biologia pela Universidad de Los Andes, Colômbia, mestrado e doutorado em Geografia pela Universidade de São Paulo. Atualmente é Professora Adjunta do Departamento de Geografia da Universidade de Brasília.

Recebido para publicação em 9 de novembro de 2016. Aceito para publicação em 3 de janeiro de 2017. 